\title{
Audiovestibular Changes in Diabetes Mellitus
}

\author{
D. R. Sharma, A.K. Gupta, R.K. Saxena, C. Mohan, M.L. Sharma, Associate Professor, \\ Department of ENT, I.G. Medical College, Shimla - 171001
}

\section{|||||||||||||||||||||||||||||||||||||||||||||||||||||||||||||||||||||||||||||||||||||||||||||||||||||||||||||||| $\mid$}

\begin{abstract}
Audiovestibular functions in 50 cases of diabetes mellitus have been evaluated to find out the type of hearing loss. Diabetes mellitus causes a significant bilateral symmetrical hearing loss at higher frequencies and with the progress of disease and added complications the hearing further deteriorates. On control of diabetes hearing changes are found to be irreversible. However vestibular functions remain uninvolved in cases of diabetes mellitus. A direct correlation was found between hearing loss and increasing blood sugar level.
\end{abstract}

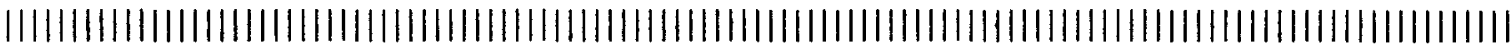

D iabetes mellitus has been described for some 3500 years, but neurological disorders associated with the disease were recorded in 1798 by John Rollo. The relationship between diabetes mellitus and audiovestibular organs are known for more than 100 years. Jordao (1857) was the first to report a case of incipient diabetic coma in a 41 years old man exhibiting impairement of vision, hearing, smell and taste. Marchal de Calvi (1864) also observed neurologic disorders in diabetes mellitus and sensorineural deafness has caused much controversy with reference to the site of lesion and degree of hearing loss. The literature exhibits many contradictions concerning the correlation between hearing impairment and diabetic manifestations.

\section{Material and Method}

The present study has been under taken to de- termine the audiovestibular profile in cases of diabetes mellitus. In this study 25 age and sex matched healthy subjects as control (group -1) have been evaluated along with 25 diagnosed cases of diabetes mellitus Group (II) and 25 cases of diabetes mellitus with complications like peripheral neuropathy, non healing ulcer, hemiparesis, recurrent fungal infection etc. Group (III), with a view to assessing audiovestibular profile of the cases. Patients with a history or finding indicative of any otological pathology have been excluded from the study. To exclude cases of presbyacusis the study has been done in fairly young diabetics. All the patients included in the study were subjected to a thorough systemic and ENT examinations. The criteria for diagnosis of diabetes mellitus was based on history, clinical examination and biochemical investigations. Audiological evaluation was done by pure tone audiometery (Arphi audiometer Model 700 MK- 
IV type) SISI \& tone decay test. Evaluation of vestibular functions was done by differential caloric test (Fitzgeraled and Hall Pike - 1942). The control and diabetic groups consist of 13 male and 12 females, with age range from 20 50 years.

\section{Observations}

The present study consists of 3 groups of cases, group-I (Control), Group-1I (diabetes mellitus) and Group-III (diabetes mellitus with complications). In each group there were 13 males and 12 females with age ranging from 20-50 years. In Group-III cases a variety of one or more diabetic complication were seen. The predominant being retinopathy $(48 \%)$, neuropathy $(44 \%)$, and nephropathy $(44 \%)$. None of the patients gave any history of vestibular involvement. However 4 patients volunteered history of hearing loss. On pure tone audiometery hearing loss was found in 24 cases (48\%) Table I.

\section{Table - 1 .}

Age wise distribution of Patients

\begin{tabular}{lccc}
\hline Age range & $\begin{array}{c}\text { No. of } \\
\text { Cases }\end{array}$ & $\begin{array}{c}\text { Hearing } \\
\text { loss }\end{array}$ & $\begin{array}{c}\text { No. of cases with } \\
\text { hearing loss }\end{array}$ \\
\hline $21-30$ Yrs & 13 & 7 & $53.8 \%$ \\
\hline $30-40$ Yrs & 18 & 6 & $33.3 \%$ \\
\hline $41-50$ Yrs & 19 & 11 & $57.8 \%$ \\
\hline
\end{tabular}

Hearing loss was found to be bilateral symmetrical and sensorineural in type. The number of cases with hearing loss was more in 41 50 years age group $(57.8 \%)$. The hearing loss was mild in 16 cases $(66.6 \%)$ moderate in 5 cases $(20.8 \%)$ and severe in 3 cases $(12.5 \%)$ on speech frequencies.

All the cases had abnormal tone decay suggestive of retrocochlear lesions Table II.

\section{Table - II}

\section{Correlation of Tone Decay of different Groups}

\begin{tabular}{lrrrr}
\hline Frequencies & Hz & Gr. I & Gr. II & Gr. III \\
\hline 1000 & Mean & 3.000 & 22.200 & 22.200 \\
& S.D. & \pm 1.936 & \pm 7.916 & \pm 7.716 \\
& & $P<0.05$ & & $P \geq 0.05$ \\
\hline 2000 & Mean & 3.000 & 25.200 & 24.000 \\
& S.D. & \pm 1.936 & \pm 7.427 & \pm 6.614 \\
& & P<0.05 & & $P \geq 0.05$ \\
\hline 4000 & Mean & 2.667 & 26.600 & 25.800 \\
& S.D. & \pm 1.484 & \pm 6.570 & \pm 8.622 \\
& & P<0.05 & & P $\geq 0.05$ \\
\hline
\end{tabular}

The hearing loss was found to be more in the diabetic with higher blood sugar level Table III.

With control of diabetes there was no improvement in hearing loss. Hearing threshold at different frequencies for air conduction and bone conduction both ears, there was a constant hearing loss upto $4000 \mathrm{~Hz}$ followed by a sudden fall in hearing threshold Fig.-I. In Group III

Table - III

Correlation of Blood Sugar Level and Hearing Loss

\begin{tabular}{lcrrr}
\hline $\begin{array}{l}\text { Fasting Blood } \\
\text { Sugar level } \\
\text { mgm\% }\end{array}$ & $\begin{array}{c}\text { No. of } \\
\text { Cases }\end{array}$ & $\begin{array}{c}\text { Normal } \\
\text { Hearing }\end{array}$ & $\begin{array}{c}\text { Impaired } \\
\text { Hearing }\end{array}$ & \multicolumn{1}{c}{$\begin{array}{l}\text { Type of } \\
\text { Hearing loss } \\
\text { (HL) }\end{array}$} \\
\hline $\begin{array}{c}100 \mathrm{mg} \% \\
\text { (normal) }\end{array}$ & 25 & $25(100 \%)$ & & \\
\hline $100-150$ & 10 & $6(60 \%)$ & $4(40 \%)$ & Sensorineural (SN) \\
\hline $151-200$ & 15 & $8(53.3 \%)$ & $7(46.6 \%)$ & S.N.HL \\
\hline $201-250$ & 10 & $4(40 \%)$ & $6(60 \%)$ & S.N.HL \\
\hline$>250$ & 15 & $7(46.7 \%)$ & $8(53.3 \%)$ & S.N.HL \\
\hline
\end{tabular}


cases one or more complications were seen in all the cases. The number of cases with hearing loss was found to be more in Group III. Out of 24 diabetic cases showing hearing loss 6 cases were in Group II, 18 cases $(75 \%)$ of diabetics were in Group III. On correlation of age and sex with hearing loss no difference between audiovestibular functions has been found in any dge group or between the sexes.
In the present study statistically no difference in audiovestibular functions was found neither in any age group nor between the sexes. The audiological profile of control group was essentially within normal limits and the mean hearing threshold in diabetics on statistical analysis showed a significant statistical difference $(P<0.05)$.

Table - IV

Comparative Value of Hearing Thresholds of Group II, III

\begin{tabular}{c|c|c|c|c|c}
\hline \multirow{2}{*}{ Frequencies $\mathrm{Hz}$} & \multicolumn{2}{|c|}{ Mean } & \multicolumn{2}{c|}{ S.D. } & \multirow{2}{*}{ P } \\
\cline { 2 - 5 } & Gr. II & Gr.III & Gr. II & Gr. III & \\
\hline 250 & 8.100 & 11.200 & 9.085 & 8.426 & $<0.05$ \\
\hline 500 & 10.200 & 13.700 & 8.142 & 6.911 & $<0.05$ \\
\hline 1000 & 12.100 & 15.800 & 7.633 & 7.379 & $<0.05$ \\
\hline 2000 & 16.900 & 19.100 & 9.577 & 8.249 & $<0.05$ \\
\hline 4000 & 22.900 & 24.900 & 10.599 & 9.819 & $<0.05$ \\
\hline 8000 & 39.060 & 46.460 & 18.485 & 17.843 & $<0.05$ \\
\hline
\end{tabular}

When hearing threshold of Group II and III were compared (Table-IV), it was found that there was a statistical difference $(P<0.05)$ of hearing threshold at all the frequencies. From Table$V$ it is clear that in the diabetic patients there is a bilateral symmetrial high tone sensorineu- ral deafness and it is more significant when the hearing threshold of diabetic patients was compared to normal. It involves all the frequencies. The cmparative values of short increment sensitivity index of three groups is shown in Table $V$.

Table - V

Comparative Values of SISI Scores of three Groups

\begin{tabular}{rrrrr}
\hline \multicolumn{2}{c}{ Frequencies Hz } & Gr.I & Gr.II & Gr.III \\
\hline \multirow{2}{*}{1000} & Mean & 3,500 & 18.400 & 18.200 \\
& S.D. & \pm 2.803 & \pm 5.858 & +4.361 \\
& S.E. & 0.724 & 1.172 & 0.872 \\
\hline \multirow{2}{*}{2000} & Mean & 3.833 & 17.800 & 15.200 \\
& S.D. & \pm 2.650 & \pm 7.264 & +3.139 \\
& S.E. & 0.684 & 1.453 & 0.628 \\
\hline \multirow{2}{*}{4000} & Mean & 3.167 & 17.800 & 15.200 \\
& S.D. & \pm 2.582 & \pm 7.264 & +2.492 \\
& S.E. & 0.670 & 1.453 & 0.498 \\
\hline
\end{tabular}


Table- $V$ shows that there is a statistical difference $(\mid<0.05)$ in SISI score of Group I and III but there was no statistical difference $(P<0.05)$ when Group II and III were compared. On comparison of tone decay test in Group II and Group III it is inferred that the type of deainess is of retrocochlear type.

The comparative values of tone decay at 1000 , 2000 and $4000 \mathrm{~Hz}$ for Group I and II, Group II and III are shown in Table II. It is found that there is a statistical difference $(P<0.05)$ when Group II and Group III are compared.

A positive correlation has been found between hearing threshold and blood sugar level. With the increasing blood sugar level there is a constant increase of deainess. But the vestibular system remains unaffected. These findings of noninvolvement of vestibular system have also been observed by Jorgensen \& Buch (1961).

\section{Discussion}

The audiological profile of diabetic cases has been found to be controversial over the years. The type and range of hearing loss has differed widely, in numerous studies.

The present study has revealed no differences in audiovestibular profile in different age group not between sexes of the diabetic patients. These observations are contrary to Shaia and Sheehy (1976) Taylor and Urwin (1978) who observed more hearing loss in females than males. Camisca (1950) and Dietzel (1964) found more deafness in males. Axelsson and $F$ zgerberg (1962) found no difference between the sexes.

All the cases showed sensorineural deafness, retrocochlear type which is bilaterally symmetrical and more at higher frequencies. Axelsson and Fagerberg (1968) have also observed retrochlear type of deafness. Fedele et al (1983) and Panda et al (1987) have described involvement of somatic, autonomic and central nervous system on brain steam evoked response studies in diabetes mellitus. Jorgenson et al (1961) have stressed upon the theory of cochlear type of deafness due to angiopathy in diabetes mellitus.

Triana et al (1991) also described loss of sensory hair cells in cochlea in diabetics resulting in cochlear hearing loss. The cochlear or retrocochlear deafness in cases of diabetes mellitus cases may be explained on the hypothesis of microangiopathy or neuropathy which is a well known phenomenon in cases of diabetes mellitus. Whertherin (1929) and Benesi and Somer (1929) suggested that the deafness is caused by combination of cochlear and retrocochlear type of lesions.

The hearing loss was found to be irreversible, with control of diabetes. No evidence of vestibular dysfunction was found in diabetics. Probably vestibular structures are resistant to ischeamia as suggested by Sander et al (1982). 


\section{||||$|+|||||||||||||||||||||||||||||||||||||||||||||||||||||||||||||||||||||||||||||||||||||||||||||||||||||||||||||$}

\section{References}

1. Axelsson A et al (1978): Hearing in diabetics. Acts larybgol Suppl. 356.

2. Blumenthal HT, Berns AW, Goldenber, ABS et al (1966): Etiologic considerations. Peripheral Vascular disease of the Lower extremities with special reference to Diabetes Mellitus. Circulation $33: 98$ - 106.

3. Costs OA (1967): Inner ear pathology in experimental diabetes. Laryngoscope 77: 08 - 75.

4. Friedman SA, Schulman RH, Weies S (1975): Hearing and diabetic neuropathy. Arch Inter Med $135: 573-576$.

5. Jorden WR (1936): Neuritic Manifestation of diabetes mellitus. Archives of internal medicine 57: $307-366$.

6. Jorgensen MB, Buch NH (1961): Studies of Inner ear function and cranial nerves in diabetes. Acts otolaryng 53: $350-364$.

7. Jorgensen $M B$ (1961): The inner ear in diabetes mellitus. Archieves of Otolaryngology 74: $373-381$.

8. Kovar M (1973): The Inner ear in diabetes mellitus. Otorhinolaryngol 35: 42 - 51.

9. Kurian M. Thomas K, Bhanu TS (1989): Hearing threshold in patients with diabetes mellitus. The journal of laryngology \& Otology $103: 160-168$.

10. Larson DL, Auchincloss JH (1950): Multiple symmetric bilateral cranial nerve Palsies in patients with unregulated diabetes mellitus. Archives of internal Medicine : 265-271.

11. Panda N, Prabhakar $S(1987)^{\circ}$ : Brain stem evoked responses in diabetes. Indian journal of Otolaryngology 39: 18.

12. Sharma YP, Mann SBS et al. (1981): Brain stem evoked response audiometry in diabetes mellitus. Indian Journal of Otolarynogology 39: 8763-166.

13. Taylor IG, Irwin J (1978): Some Audiological aspects of diabetes mellitus. Journal of largyology and Otology $92: 99-113$.

14. Verma A, Bisht MS, Ahuja GK (1984): Involvement of Central nervous systeam in diabetes mellitus. Journal of Neurology, Neurosurgery and Psychiatry 47: $416-419$. 